Acta Crystallographica Section D

Biological Crystallography

ISSN 0907-4449

\section{Crystallization and preliminary crystallographic analysis of the fusion core from two new zoonotic paramyxoviruses, Nipah virus and Hendra virus}

Highly conserved heptad-repeat (HR1 and HR2) regions in class I Received 10 February 2004 Accepted 20 April 2004

viral fusion $(\mathrm{F})$ proteins, including the $\mathrm{F}$ protein from paramyxovirus,
Yanhui Xu, ${ }^{a}$ Zhiyong Lou, ${ }^{\text {a }}$ Yiwei Liu, ${ }^{a}$ David K. Cole, ${ }^{b}$ Nan Su, ${ }^{a}$ Lan Qin, ${ }^{\mathrm{a}} \mathrm{Xu} \mathrm{Li}{ }^{\mathrm{a}}$ Zhihong Bai, ${ }^{\mathrm{a}}$ Zihe Rao ${ }^{\mathrm{a} *}$ and George F. Gao ${ }^{\mathrm{b}_{*}}$

a Laboratory of Structural Biology and MOE Laboratory of Protein Sciences, School of Life Sciences and Bio-Engineering, Tsinghua University, Beijing 100084, People's Republic of China, and ${ }^{\mathbf{b}}$ Nuffield Department of Clinical Medicine, John Radcliffe Hospital, University of Oxford, Oxford OX3 9DU, England

Correspondence e-mail: raozh@xtal.tsinghua.edu, ggao@gwmail.jr2.ox.ac.uk
C 2004 International Union of Crystallography Printed in Denmark - all rights reserved interact with each other post-fusion to form a six-helix bundle called a fusion core. Crystals of the fusion core of Nipah virus have been grown at $291 \mathrm{~K}$ using PEG 4000 as precipitant. The diffraction pattern of the crystal extends to $2.1 \AA$ resolution at $100 \mathrm{~K}$ in-house. The crystals have unit-cell parameters $a=31.664, b=31.725, c=51.256 \AA$, $\alpha=80.706, \beta=86.343, \gamma=65.812^{\circ}$ and belong to space group $P 1$. Crystals of the fusion core of Hendra virus have also been grown at $291 \mathrm{~K}$ using PEG 4000 as precipitant. The diffraction pattern of the crystal extends to $2.0 \AA$ resolution at $100 \mathrm{~K}$ in-house. A selenomethionine (SeMet) derivative of the $\mathrm{HeV}$ fusion core was overexpressed using the same Escherichia coli expression system and purified. The derivative crystals were obtained under similar conditions and three different wavelength data sets were collected to $2.0 \AA$ resolution from the derivative crystal at BSRF (Beijing Synchrotron Radiation Facility). The crystals have unit-cell parameters $a=31.997, b=31.970, c=53.865 \AA$, $\alpha=85.990, \beta=85.842$, $\gamma=68.245^{\circ}$ and belong to space group $P 1$.

\section{Introduction}

Nipah virus (NiV) and Hendra virus $(\mathrm{HeV})$ are newly emergent zoonotic members of the Paramyxoviridae family (Murray, Rogers et al., 1995; Murray, Selleck et al., 1995; Selvey et al., 1995; Chua et al., 1999, 2000; Harcourt et al., 2000). They have several distinct characteristics when compared with other known members of the Paramyxoviridae and a new genus has therefore been proposed for them, the genus Henipavirus (Wang et al., 2000, 2001; Chan et al., 2001). Paramyxoviruses are a group of enveloped negative-stranded RNA viruses. Their infection is mediated by their fusion glycoproteins through membrane fusion.

The fusion glycoproteins of enveloped viruses such as the paramyxoviruses, which are typically type I integral membrane proteins, are encoded by the virus and synthesized by the infected cell (reviewed in Eckert \& Kim, 2001). NiV and HeV F proteins share many common features with homologous proteins in the Paramyxoviridae, Retroviridae and Filovirdae families (Wang et al., 2000, 2001; Chan et al., 2001; Eckert \& Kim, 2001). They are synthesized as an inactive precursor $\left(\mathrm{F}_{0}\right)$ and then cleaved by an intracellular proteolytic enzyme into two disulfide-bond-linked subunits. These are termed the distal subunit $\mathrm{F}_{2}$ and the transmembrane subunit $F_{1}$, which possesses a highly hydrophobic conserved region called the fusion peptide and two heptad-repeat regions (HR1 and HR2), one
(HR1 or HRA) adjacent to the fusion peptide and the other (HR2 or HRB) adjacent to the transmembrane (TM) domain of the $\mathrm{F}_{1}$ subunit (Michalski et al., 2000; Tamin et al., 2002). It is believed that the two HR domains refold into a six-helix bundle during the fusion process, in which the HR1 domain forms a trimeric coiled coil surrounded by three antiparallel helices of the HR2 domain (reviewed in Eckert \& Kim, 2001). Consequently, the transmembrane domain and the fusion peptide, which is known to insert into the cell membrane, are both transposed into close association. This pulls the cellular and viral membrane into proximity, facilitating membrane fusion. This six-helix bundle is called the virus fusion core (reviewed in Eckert \& Kim, 2001). Our previous biochemical and biophysical analysis has demonstrated that the heptad-repeat peptides of the $\mathrm{NiV}$ and $\mathrm{HeV}$ fusion proteins both form a typical six-helix bundle (Xu et al., 2004).

In this report, we describe the crystallization and preliminary X-ray diffraction studies of the fusion cores (the six-helix bundles of the HR1 and HR2 complex) of both the $\mathrm{NiV}$ and $\mathrm{HeV}$ fusion proteins.

\section{Materials and methods}

\subsection{Preparation of the fusion cores}

The fusion cores of both the $\mathrm{NiV}$ and $\mathrm{HeV}$ fusion proteins were prepared as a single chain by linking the HR1 and HR2 domains via an 
eight-amino-acid linker (GGSGGSGG). The constructs and the encoded proteins are also known as 2-Helix. The preparation and characterization of the 2-Helix proteins has been reported previously ( $\mathrm{Xu}$ et al., 2004), but the constructs were re-cloned to remove the original rhinovirus $3 \mathrm{C}$ cleavage site in order to obtain better crystals. The new constructs were cloned by PCR from the original pET-23d vector into the new pET-22b vector (Novagen). NdeI and XhoI sites were introduced by PCR as restriction sites for cloning. The 2-Helix constructs were verified by direct DNA sequencing. The primers used for making the new 2-Helix constructs were NP F, 5'-CTGACATATGGCTATGAAAAACGCTGAC-3', and NP R, 5'-ATGACTCGAGAACGGTGTCCAGCAGACG-3'.

The protein expression and Ni-affinity purification were essentially performed as described previously (Xu et al., 2004). Briefly, the plasmids were transformed into BL21 (DE3) competent cells and the cells were cultured at $310 \mathrm{~K}$ in $2 \times \mathrm{YT}$ medium containing $100 \mu \mathrm{g} \mathrm{ml}^{-1}$ ampicillin. When the culture density $\left(A_{600}\right)$ reached to $0.6-0.8$, the culture was induced with $0.2 \mathrm{~m} M$ IPTG and grown for an additional $10 \mathrm{~h}$ at $289 \mathrm{~K}$ before the cells were harvested.

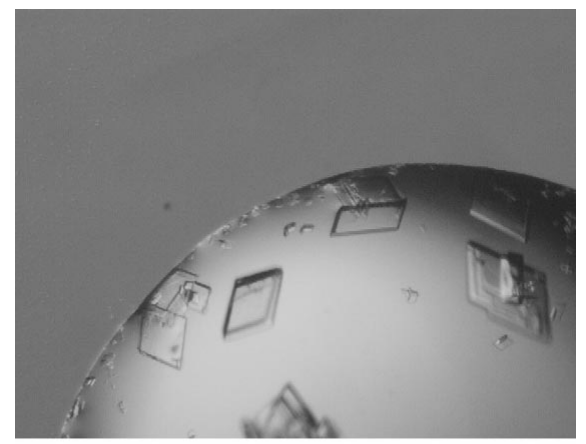

(a)

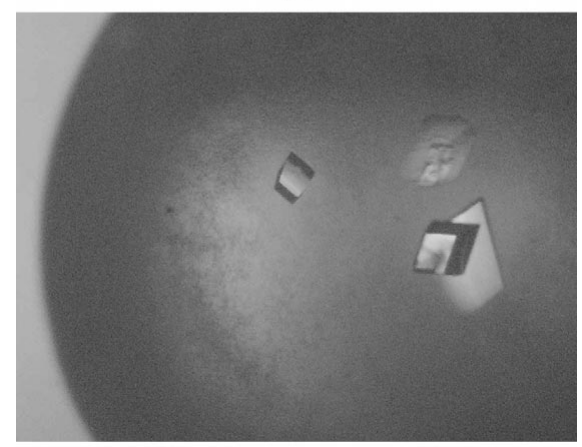

(b)

Figure 1

(a) Typical crystals of the NiV 2-Helix protein grown using the hanging-drop method in $29 \%$ PEG 4000 , $0.1 M$ Tris $\mathrm{pH}$ 8.5. (b) Typical crystals of the HEV 2Helix protein grown using the hanging-drop method in $10 \%$ PEG 4000, $0.1 M$ HEPES pH 6.5 .
The bacterial cell pellet was resuspended in PBS and homogenized by sonication. The lysate was then centrifuged at $18000 \mathrm{~g}$ for $20 \mathrm{~min}$ at $277 \mathrm{~K}$ and the supernatant was loaded onto an $\mathrm{Ni}^{2+}-\mathrm{NTA}$ column (Qiagen). The contaminated protein was washed with washing buffer $(1 \times \mathrm{PBS}, 60 \mathrm{~m} M$ imidazole $)$ and the target protein was eluted with elution buffer $(1 \times$ PBS, $500 \mathrm{~m} M$ imidazole $)$. The protein purified by affinity chromatography was further purified by a gel-filtration run on a Superdex G75 column (Pharmacia) and analyzed by SDS-PAGE.

The selenomethionine derivative of the $\mathrm{HeV}$ 2-Helix was expressed in minimal media M9 containing $30 \mathrm{mg} \mathrm{l}^{-1}$ L-SetMet. A further six amino acids (lysine, threonine, phenylalanine, leucine, isoleucine and valine) were added to the culture for inhibition of Met biosynthesis of the BL21 (DE3) expression strain. Purification of the selenomethionene $\mathrm{HeV}$ 2-Helix was performed as for the native protein. The

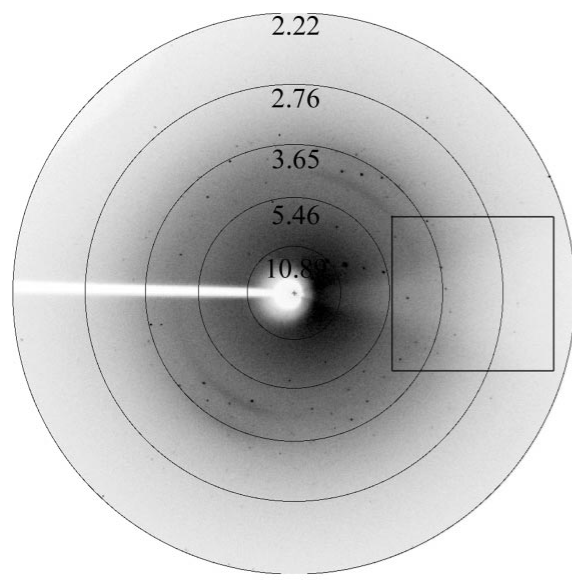

(a)

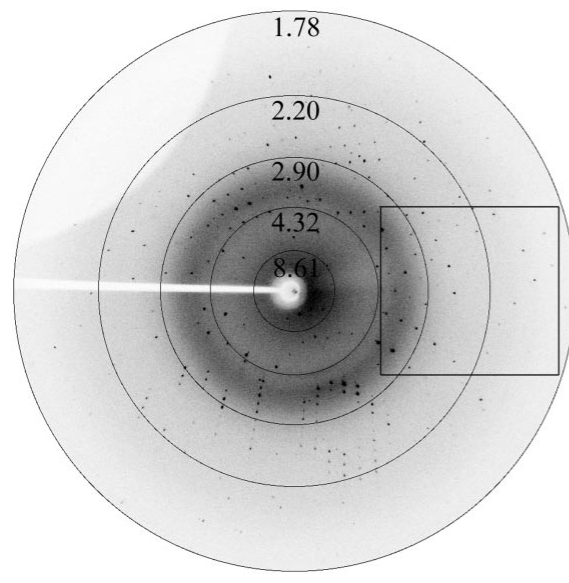

(c) incorporation of selenium was confirmed by mass-spectrometric analysis.

\subsection{Crystallization}

The purified protein was dialyzed into crystallization buffer $(10 \mathrm{~m} M$ Tris- $\mathrm{HCl} \mathrm{pH}$ $8.0,10 \mathrm{mM} \mathrm{NaCl}$ ) and concentrated to 10 $15 \mathrm{mg} \mathrm{ml}^{-1}$. Protein concentrations were determined by absorbance at $280 \mathrm{~nm}$, assuming an $A_{280}$ of 0.393 for a $1.0 \mathrm{mg} \mathrm{ml}^{-1}$ solution. Initial crystallization conditions were screened using Crystal Screen (Hampton Research). The protein could be crystallized under several conditions. The conditions yielding small crystals were further optimized by changing the precipitant and protein concentration and the Buffer pH. NiV 2-Helix crystals of good quality could be obtained in $0.1 \mathrm{M}$ Tris- $\mathrm{HCl}$ pH 8.5, 29\%(v/v) PEG 4000; HeV 2-Helix crystals of good quality could be obtained in $0.1 M$ HEPES pH 6.5, 10\%(v/v) PEG 4000.

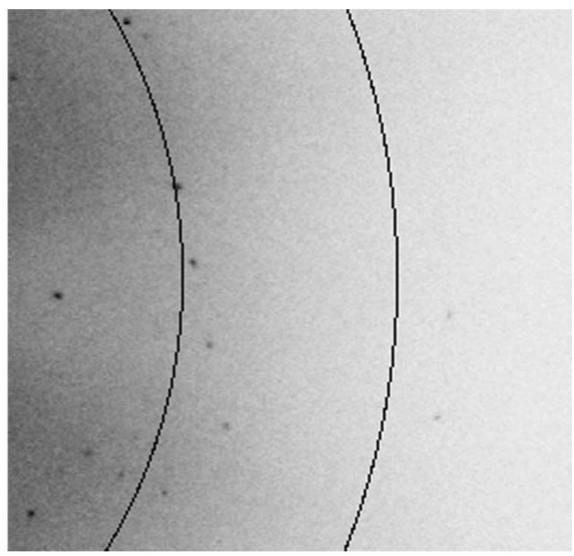

(b)

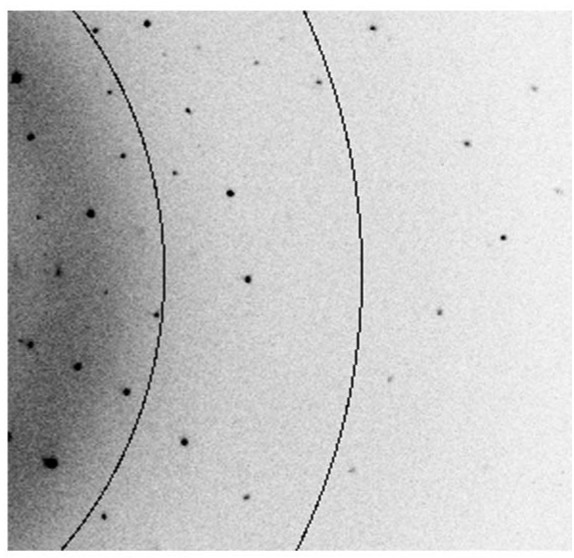

(d)

Figure 2

(a) A typical X-ray diffraction pattern from a crystal of NiV 2-Helix. The diffraction image was collected on a MAR Research image-plate detector. The oscillation range is $1^{\circ}$. (b) An enlarged image of the area indicated in (a). (c) A typical X-ray diffraction pattern from a crystal of HeV 2-Helix. The diffraction image was collected on a MAR Research image-plate detector. The oscillation range is $1^{\circ} .(d)$ An enlarged image of the area indicated in $(c)$. 
Table 1

Data collection and processing statistics of the fusion cores of $\mathrm{NiV}$ and $\mathrm{HeV}$.

\begin{tabular}{|c|c|c|c|c|}
\hline \multirow[b]{2}{*}{ Data } & \multicolumn{3}{|l|}{$\mathrm{HeV}$} & \multirow[b]{2}{*}{$\mathrm{NiV}$} \\
\hline & Peak & Edge & Remote & \\
\hline Space group & $P 1$ & $P 1$ & $P 1$ & $P 1$ \\
\hline \multicolumn{5}{|l|}{ Unit-cell parameters } \\
\hline$a(\AA)$ & 31.938 & 31.997 & 33.003 & 31.664 \\
\hline$b(\AA)$ & 31.965 & 31.970 & 33.160 & 31.725 \\
\hline$c(\AA)$ & 53.321 & 53.865 & 55.618 & 51.256 \\
\hline$\alpha\left({ }^{\circ}\right)$ & 86.186 & 85.990 & 84.957 & 80.706 \\
\hline$\beta\left(^{\circ}\right)$ & 85.848 & 85.842 & 86.701 & 86.343 \\
\hline$\gamma\left({ }^{\circ}\right)$ & 68.127 & 68.245 & 69.053 & 65.812 \\
\hline Wavelength $(\AA)$ & 0.9799 & 0.9801 & 0.9500 & 1.5418 \\
\hline \multicolumn{5}{|l|}{ Resolution range $(\AA)$} \\
\hline Overall & $50-2.1$ & $50-2.1$ & $50-2.35$ & $35-2.2$ \\
\hline Lowest shell & $50-4.52$ & $50-4.52$ & $50-5.06$ & $35-4.74$ \\
\hline Highest shell & $2.18-2.10$ & $2.18-2.10$ & $2.43-2.35$ & $2.28-2.20$ \\
\hline Reflections observed & 84348 & 97509 & 88705 & 27810 \\
\hline Unique reflections & 11172 & 13019 & 12545 & 8630 \\
\hline \multicolumn{5}{|l|}{ Completeness $(\%)$} \\
\hline Overall & 98.0 & 98.1 & 97.9 & 94.7 \\
\hline Lowest shell & 99.4 & 99.4 & 99.0 & 96.8 \\
\hline Highest shell & 96.9 & 96.9 & 97.3 & 91.0 \\
\hline \multicolumn{5}{|l|}{$I / \sigma(I)$} \\
\hline Overall & 10.5 & 10.3 & 10.6 & 8.2 \\
\hline Lowest shell & 15.1 & 15.1 & 13.2 & 11.0 \\
\hline Highest shell & 3.3 & 3.5 & 3.2 & 2.8 \\
\hline Redundancy & 7.6 & 7.5 & 7.1 & 3.2 \\
\hline \multicolumn{5}{|l|}{$R_{\text {merge }}(\%)$} \\
\hline Overall & 13.4 & 13.7 & 14.2 & 7.1 \\
\hline Lowest shell & 8.2 & 8.3 & 8.4 & 4.2 \\
\hline Highest shell & 45.5 & 41.3 & 49.3 & 37.4 \\
\hline Overall temperature factor $\dagger\left(\AA^{2}\right)$ & 22.9 & & & 34.8 \\
\hline
\end{tabular}

$\dagger$ Estimated from the Wilson plot.

Crystallization was performed using the hanging-drop vapour-diffusion method at $291 \mathrm{~K} .1 \mu \mathrm{l}$ protein solution was mixed with $1 \mu \mathrm{l}$ reservoir solution and the mixture was equilibrated against $200 \mu \mathrm{l}$ reservoir solution at $291 \mathrm{~K}$. The crystals appeared in 3-5 d.

The purified HeV 2-Helix selenomethionine derivative was concentrated to $8 \mathrm{mg} \mathrm{ml}^{-1}$. Crystallization trials were set up based on the optimized conditions used for native protein.

\subsection{Data collection and processing}

Data collection of NiV 2-Helix was performed in-house on a Rigaku RU2000 rotating copper-anode $\mathrm{X}$-ray generator operated at $48 \mathrm{kV}$ and $98 \mathrm{~mA}(\mathrm{Cu} \mathrm{K \alpha}$; $\lambda=1.5418 \AA$ ) with a MAR 345 image-plate detector. The crystal was mounted on a nylon loop and flash-frozen in a cold nitrogen-gas stream at $100 \mathrm{~K}$ using an Oxford Cryosystems cryocooler with reservoir solution as the cryoprotectant. Data were indexed and scaled using $D E N Z O$ and SCALEPACK (Otwinowski \& Minor, 1997).

The HeV 2-Helix selenomethioninederivative crystal was mounted on a nylon loop and flash-frozen in a cold nitrogen-gas stream at $100 \mathrm{~K}$ using an Oxford Cryosystems cryocooler with $0.1 M$ HEPES pH 6.5,
25\% PEG 400 as cryoprotectant. Data collection was performed by a rotation method using a MAR CCD detector with synchrotron radiation on BSRF (beamline 3W1A of Beijing Synchrotron Radiation Facility). Data were indexed and scaled using DENZO and SCALEPACK (Otwinowski \& Minor, 1997).

\section{Results and discussion}

The 2-Helix proteins of $\mathrm{NiV}$ and $\mathrm{HeV}$ can easily be crystallized under several conditions. However, good-quality crystals of $\mathrm{NiV}$ 2-Helix could only be obtained with $0.1 \mathrm{M}$ Tris $\mathrm{pH} 8.5,29 \%(v / v)$ PEG 4000 (Fig. 1a). For HeV 2-Helix and its selenomethionine derivative, the only conditions under which good-quality crystals could be obtained were $0.1 M$ HEPES pH 6.5, 10\%(v/v) PEG 4000 (Fig. 1b). The NiV crystals belong to space group $P 1$, with unit-cell parameters $a=31.664, b=31.725, c=51.256 \AA$, $\alpha=80.706, \beta=86.343, \gamma=65.812^{\circ}$ (Figs. $2 a$ and $2 b$ ). Assuming the presence of three molecules (one stable trimer) in the asymmetric unit, the solvent content is calculated to be about $21.1 \%$ and the Matthews number $\left(V_{\mathrm{M}}\right)$ is about $1.5 \AA^{3} \mathrm{Da}^{-1}$. The $\mathrm{HeV}$ selenomethionine-derivative crystals belong to space group $P 1$, with unitcell parameters $a=31.997, b=31.970$, $c=53.865 \AA, \alpha=85.990, \beta=85.842$, $\gamma=68.245^{\circ}$ (Figs. $2 c$ and $2 d$ ). Assuming the presence of three molecules (one stable trimer) in the asymmetric unit, the solvent content is calculated to be about $25.8 \%$ and the Matthews number $\left(V_{\mathrm{M}}\right)$ is about $1.7 \AA^{3} \mathrm{Da}^{-1}$. Selected data statistics are shown in Table 1.

Multiple-wavelength anomalous dispersion (MAD) data of $\mathrm{HeV}$ were collected from a single selenomethionine-derivative crystal using synchrotron radiation on BSRF (beamline 3W1A of the Beijing Synchrotron Radiation Facility) at peak (0.9799 $\AA$ ), inflection (0.9801 $\AA$ ) and remote $(0.950 \AA)$ wavelengths to $2.1 \AA$ using a MAR CCD detector. The crystal-to-detector distance was $80 \mathrm{~mm}$, the exposure time was approximately $60 \mathrm{~s}$ and the oscillation angle was $3^{\circ}$. Reflections with intensities of $I / \sigma(I)>3$ were analyzed to $2.1 \AA$

$\mathrm{X}$-ray diffraction data were collected from a single crystal of NiV using a Rigaku RU2000 rotating copper-anode X-ray generator and a MAR 345 image-plate detector. The crystal-to-detector distance was $120 \mathrm{~mm}$, the exposure time was approximately $600 \mathrm{~s}$, the oscillation angle was $1^{\circ}$ and the wavelength was $1.5418 \AA$.

The data were indexed and reduced online using DENZO and SCALEPACK (Otwinowski \& Minor, 1997). The structures of the NiV 2-Helix and HeV 2-Helix have been solved and will be published elsewhere. Clear structural analysis of the six-helix bundles of $\mathrm{NiV}$ and $\mathrm{HeV}$ will provide a detailed picture of the viral fusion-core structure and the molecular mechanism underlying the interchangeable interaction of HR1 with both $\mathrm{NiV}$ and HeV HR2. This will inevitably add to the repertoire of paramyxovirus six-helix bundle fusion-core structures, only two of which are available at present (those of RSV and SV5). This will also open a new avenue towards the structure-based design of fusion-inhibitor peptides or peptide analogues, e.g. small molecules, for these emerging infectious diseases.

This work was supported by Project 973 of the Ministry of Science and Technology of China (Grant No. G1999011902). GFG's stay at Tsinghua University was supported by the Chunhui Project Scheme of the Ministry of Education, People's Republic of China.

\section{References}

Chan, Y. P., Chua, K. B., Koh, C. L., Lim, M. E. \& Lam, S. K. (2001). J. Gen. Virol. 82, 2151-2155. 
Chua, K. B. et al. (2000). Science, 288, 1432-1435.

Chua, K. B., Goh, K. J., Wong, K. T., Kamarulzaman, A., Tan, P. S., Ksiazek, T. G., Zaki, S. R., Paul, G., Lam S. K. \& Tan, C. T. (1999). Lancet, 354, 1257-1259.

Eckert, D. M. \& Kim, P. S. (2001). Annu. Rev. Biochem. 70, 777-810.

Harcourt, B. H., Tamin, A., Ksiazek, T. G., Rollin, P. E., Anderson, L. J., Bellini, W. J. \& Rota, P. A. (2000). Virology, 271, 334-349.

Michalski, W. P., Crameri, G., Wang, L., Shiell, B. J. \& Eaton, B. (2000). Virus Res. 69, 83-93.

Murray, K., Rogers, R., Selvey, L., Selleck, P.,
Hyatt, A., Gould, A., Gleeson, L., Hooper, P. \& Westbury, H. (1995). Emerg. Infect. Dis. 1, 3133.

Murray, K., Selleck, P., Hooper, P., Hyatt, A., Gould, A., Gleeson, L., Westbury, H., Hiley, L., Selvey, L., Rodwell, B. \& Ketterer, P. (1995). Science, 268, 94-97.

Otwinowski, Z. \& Minor, W. (1997). Methods Enzymol. 276, 307-326.

Selvey, L. A., Wells, R. M., McCormack, J. G., Ansford, A. J., Murray, K., Rogers, R. J., Lavercombe, P. S., Selleck, P. \& Sheridan, J. W. (1995). Med. J. Aust. 162, 642-645.
Tamin, A., Harcourt, B. H., Ksiazek, T. G., Rollin, P. E., Bellini, W. J. \& Rota, P. A. (2002). Virology, 296, 190-200.

Wang, L., Harcourt, B. H., Yu, M., Tamin, A., Rota, P. A., Bellini, W. J. \& Eaton, B. T. (2001). Microbes Infect. 3, 279-287.

Wang, L. F., Yu, M., Hansson, E., Pritchard, L. I., Shiell, B., Michalski, W. P. \& Eaton, B. T. (2000). J. Virol. 74, 9972-9979.

Xu, Y., Gao, S., Cole, D. K., Zhu, J., Su, N., Wang, H., Gao, G. F. \& Rao, Z. (2004). Biochem. Biophys. Res. Commun. 315, 664670. 